\title{
A Proposal for a Drug Product Manufacturing Classification System (MCS) for Oral Solid Dosage
}

Forms

Michael Leane ${ }^{1}$, Kendal Pitt ${ }^{2}$, Gavin Reynolds ${ }^{3}$.

With contributions from: Jamshed Anwar ${ }^{4}$, Stuart Charlton ${ }^{1}$, Abina Crean ${ }^{5}$, Richard Creekmore ${ }^{3}$, Conrad Davies ${ }^{6}$, Tomas DeBeer ${ }^{7}$, Abdenour Djemai ${ }^{2}$, John Gamble ${ }^{1}$, Elaine Harrop Stone ${ }^{8}$, Anne Kavanagh $^{3}$, Peter Kleinebudde ${ }^{9}$, Chris Moreton ${ }^{10}$, Amrit Paudel ${ }^{11}$, Richard Storey ${ }^{3}$, Gregor Toschkoff ${ }^{11}$, Kiren Vyas ${ }^{2}$; and delegates to the Mat Sci / PEFDM seminar: "BCS to MCS: Predictions From Material Science to Manufacturing" EMCC, Nottingham, May 2013.

Bristol-Myers Squibb, Reeds Lane, Moreton, CH461QW, UK.

GlaxoSmithKline, Priory St., Ware, SG120DJ, UK.

(3) AstraZeneca, Silk Road Business Park, Charter Way, Hurdsfield Industrial Estate, Macclesfield, SK10 2NA, UK.

(4) Lancaster University, Bailrigg, Lancaster, LA1 4YB, UK.

(5) Synthesis and Solid State Pharmaceutical Solid Centre, University College Cork, Ireland.

(6) Pfizer, Ramsgate Road, Sandwich, Kent CT13 9NJ, UK.

(7) Ghent University, Harelbekestraat 72, B-9000 Ghent, Belgium.

(8) Merlin Powder Characterisation, Unit 1A Pavilion Way, Jubilee Drive, Loughborough, Leicestershire, LE11 5GW, UK.

(9) Heinrich-Heine-University, Universitätsstr. 1 / Gebäude 26.22, D-40225 Düsseldorf, Germany.

(10) FinnBrit Consulting, Waltham, MA, USA

(11) Research Center Pharmaceutical Engineering (RCPE), Inffeldgasse 13 A-8010, Graz, Austria.

\section{Abstract}

This paper proposes the development of a drug product Manufacturing Classification System (MCS) based on processing route and seeks feedback from the wider pharmaceutical science community on the best way to apply it to practice. The MCS is intended as a tool for pharmaceutical scientists to rank the feasibility of different processing routes for the manufacture of oral solid dosage forms, based on selected properties of the Active Pharmaceutical Ingredient (API) and the needs of the formulation. The proposed MCS could be used to develop a risk assessment for manufacturing based on "ideal" ranges for API physical properties and therefore indicate how robust a 
manufacturing process is likely to be in relation to those properties. The MCS will have many applications in pharmaceutical development, in particular, it will provide a common understanding of risk by defining what the "right particles" are (i.e. the physical properties of the particles that have been identified for each process route), enable the selection of the best process, and aid subsequent transfer to manufacturing. The ultimate aim is one of prediction of product developability and processability based upon previous experience. Delivery of this goal requires sharing of data from different sources to produce models of process robustness based on API physical properties. This approach fits with Quality by Design ( $Q b D)$ principles and has the potential of obtaining regulatory relief on the development of dosage forms by demonstrating that the properties of the ingoing API and excipients are within established ranges for the manufacturing process. Furthermore, this MCS has potential to facilitate product development and reduce the incidence of late stage failure, thus saving resource.

The four classes proposed are:

Class I: Direct Compression

Class II: Dry Granulation

Class III: Wet Granulation

Class IV: Other Technologies.

This proposal aims to provide a frame of reference for level of risk related to API physical properties versus drug product manufacturing process type. Two concepts in particular have been expanded upon: these being API developability and the impact of drug loading. The team has outlined the API parameters and value ranges that define the recommended manufacturing class and the likelihood of successfully developing an oral solid dosage form. As drug loading increases, API properties have an increased influence on the formulation properties and processability. The team is proposing the use of percolation (impact) levels, which may vary across different API attributes and parameters, to quantify this risk.

This paper is intended to stimulate contribution from a broad range of stakeholders across the pharmaceutical sciences to develop the MCS concept further and apply it to practice. In particular, feedback is sought on what API properties are important when selecting or modifying materials to enable an efficient pharmaceutical manufacturing process. Future work will build on 'prior art' and be a literature reference that can be used to articulate risk in a regulatory submission. 


\section{Advantages of a Manufacturing Classification System (MCS)}

Processing of a pharmaceutical oral solid dosage form places great demands on the component materials. They must mix readily into uniform blends, flow well, not adhere to surfaces, and be compacted into tablets on high-speed presses or encapsulated into capsules. Pharmaceutical development rightly focuses on factors that impact the patient. Such factors were covered by the development of the Biopharmaceutics Classification System (BCS) ${ }^{1}$. The BCS provides a scientific framework for classifying drugs based on their solubility and intestinal permeability, in combination with the in vitro dissolution characteristics of the drug product. These factors have been shown to govern the rate and extent of oral drug absorption from solid oral-dosage forms. However, the BCS does not consider attributes beyond the solubility and permeability of the active pharmaceutical ingredient (API). Many strategies for optimising exposure of poorly soluble drugs are now utilised ${ }^{2}$ but it is widely recognised that some of these strategies can make subsequent manufacture of drug product challenging. A good example is particle size reduction, which may ensure optimum exposure but may negatively impact flow and adhesion characteristics. There is therefore a need to consider, within the constraints of BCS requirements, the selection of an appropriate manufacturing technology and how API properties can be optimised to facilitate manufacturing requirements. A Manufacturing Classification System (MCS) would facilitate this process.

Both the current costs of drug development and of product failure are extremely high as development and manufacturing are highly resource intensive. Chemistry, manufacturing and control (CMC) factors comprise a significant proportion of failures of NDA applications ${ }^{3}$. A lot of knowledge currently exists with individuals and organisations based on their specific experiences, but gathering this together in the framework of a MCS would provide guidance on the best properties of a given API (molecular, particulate, surface and bulk) for a pharmaceutical process route to enable manufacture of the finished drug product. For example, it is already known that properties such as small particle size $e^{4,5}$ and needle-like morphology $y^{6,7}$ can lead to issues like poor flow $^{8}$, difficulties in blending ${ }^{5}$, and unwanted adhesion ${ }^{9}$ to surfaces such as tablet punches. These issues can have the knock-on effect of leading to failure of critical quality attributes of the final dosage form e.g. tablet defects (picking, sticking, capping), dissolution, and content uniformity failure. Managing this processing risk is made difficult by the fact that API properties frequently change over the course of drug development due to modifications in synthesis route, planned changes to more favourable polymorphic forms, downstream processing (intermediates to final product) and scale-up.

In summary, a MCS would aid product and process development and facilitate transfer to clinical and commercial manufacturing facilities, whilst providing a common understanding of risk that complements the BCS. There is a clear link between the MCS and BCS as the reproducible production of a dosage form that does not impede dissolution and subsequent absorption is critical. A further goal of a MCS would be the potential for obtaining regulatory relief on the development of dosage forms by demonstrating that the properties of the ingoing API and excipients are within established ranges suited to the specific manufacturing process. Examples of such regulatory relief could include reduced end-product testing or a streamlined approach to post-approval changes.

This paper summarises discussions and conclusions from the APS conference "BCS to MCS: Predictions From Material Science to Manufacturing" held in Nottingham in May 2013 and 
subsequent discussion within APS focus groups and the MCS working party. It is published to invite comments from the technical, scientific, and regulatory community. In particular, we are interested in finding out: What API properties do you think are important when selecting or modifying materials to enable an efficient pharmaceutical manufacturing process? Additional roundtable discussions are planned for the UKPharmSci 2014 and FIP 2015 conferences. A final position paper including comments on this article will be published after these sessions.

\section{MCS Based on Pharmaceutical Processing Routes}

Traditionally, poor API properties can be overcome in two ways. Firstly, by the addition of functional excipients specifically designed to aid processability. However, addition of excipients alone may not be able to overcome unfavourable API properties particularly when there is a high drug loading in the formulation. The second strategy is to granulate the material to form denser, larger particles which are more amenable to processing. Delegates at an Academy of Pharmaceutical Sciences event in Nottingham in May 2013 considered various outlines for a proposed MCS. Subsequently, a decision was made to explore options towards developing an MCS based on processing route. It was concluded that such a structured approach would assist formulators facing a common challenge: how to rationally select the optimum processing route for a particular API. In addition, such a MCS could assist in developing targets for designing optimised API that could then be processed using a simpler processing route. We will now elaborate in greater detail on the different processing routes intended to form the basis for a MCS.

A summary of three major conventional pharmaceutical solid oral dosage form processing routes is given in Figure 1a-c. It is proposed that these three technologies, along with a fourth category incorporating other technologies, form the basis of the MCS as follows:

1. Direct Compression (DC),

2. Dry Granulation (DG)

3. Wet Granulation (WG).

4. Other Technologies (OT)

This proposed MCS follows a similar philosophy to BCS, with the simplest manufacturing technology (DC) occupying the Class I position. As highlighted in Figure 1, moving down through Classes 1-3, there is an increase in the number of processing steps, complexity and typically, greater costs of manufacture ${ }^{10}$. The ability of the processes to accommodate unfavourable physical properties of the API also increases as you move down through the classes. However, the API may be subjected to greater stress during a more complex manufacture. These stresses include shear during milling and roller compaction, exposure to moisture during wet granulation, and heating during drying and coating. Such stresses are known to lead to changes to some API which can be problematic ${ }^{11-16}$. An additional complication is that multi-step processes also make it more challenging to identify a root cause for any problems that do occur. A fourth classification was proposed which would incorporate more complex processing routes e.g. melt granulation, active coating and spray-drying. 


\section{Drug Loading and Percolation Concept for Physical Properties}

The higher the drug loading or level of an API, the more likely it is that the properties of the API will impact the manufacturability/processability as well as the properties of the finished dosage form. This can have a marked effect on the effort required to successfully formulate. The level at which an API would impact the finished properties of the dosage form is referred to as the percolation threshold. This threshold in turn would be influenced by whether the relevant property is a surface or bulk (volume or mass) property of the API.

It may be assumed that the percolation threshold for bulk properties would change with differing API properties such as particle size, shape, surface and mechanical properties. Hence it would be expected that the percolation threshold for a given API would need to be confirmed from data specific to that API. This threshold could be determined through data generation through experimentation, computational modelling employing percolation theory tools ${ }^{17}$, or a combination of both. Comparison with APIs of similar properties could also assist in this determination. For example, blends containing micronised APIs will always have an increased risk of poor flow and unwanted surface adhesion due to their small particle size / high surface area. From experience, percolation thresholds would be low, with drug loadings higher than $20 \%$ being expected to give issues with all micronised materials in a DC or DG process. Ideally, to ensure robustness, the formulation should be designed with an appropriate buffer zone away from the percolation threshold. Values close to the threshold would run the risk of the formulation being sensitive to changes in API particle properties. It is expected that the more the percolation threshold is exceeded, then the stronger the impact of a given API property will be. Similarly, if parameters are within the percolation threshold, the more robust the process is likely to be to accommodate changes in API. It should be noted that the surface properties of some materials may have a disproportionate impact compared to their bulk properties e.g. magnesium stearate.

\section{Developability Concept}

It is recognised that DC and DG can be regarded as part of the same continuum of increasing densification and therefore there will be an overlap of the desired properties and varying degrees of risk according to the manufacturing process. WG whether by low shear, high shear or top spray methods involves more extensive modification of the API, but generally speaking the initial API and particle properties are important factors influencing the process performance. The OT classification by contrast, is reserved for materials that cannot be processed using the first three conventional routes and, by its very nature, encompasses a wide range of potential technologies which are described further in a separate section. This category recognises that the API properties need to be so extensively modified by secondary processing that it is the properties of the final construct (API alone or processed with excipient) that are critical. Indeed, the MCS may help to identify the desired target properties of these constructs to allow subsequent processing using DC, DG or WG.

The concept of developability is introduced to assess how the physicochemical properties and dose of the API aid or hinder the development of any dosage form. Table 1 summarises the properties of an API considered desirable for a DC, DG or WG process. It would be unlikely that any molecule would have all of these desired properties. However the further from these desired properties, the more difficult and risky the development would become and the more detailed the control strategy for manufacturing. References for these factors are given wherever possible. However, it is 
important to note that some of the values cannot be sourced in the literature but represent current best commercial practice. They are therefore intended as a starting point for discussion. Some may not be applicable to all development and manufacturing indications and there may be additional considerations specific to a particular API in a specific dosage form. The exact relevance of the criteria would need to be risk-assessed on an individual compound basis.

Future evolution of the MCS could involve subdividing the developability space into zones where DC, DG and WG would be the preferred processing route. It is acknowledged that these zones might not have sharp boundaries, with considerable overlap depending on the material property and the nature of the API. In the following section developability parameters considered in the evolution of the MCS are expanded upon.

\section{Developability Parameters}

Projected Dose: It is recognised that the toxicological risk is lower if the dose is less than $50 \mathrm{mg}^{18}$. This is independent of any percolation threshold considerations. When considering processability, it should be noted that achieving content uniformity can be challenging for low doses less than $1 \mathrm{mg}$. High doses can pose patient acceptability challenges due to difficulties in swallowing large tablets with an upper weight limit for currently marketed products of approximately $1.5 \mathrm{~g}$.

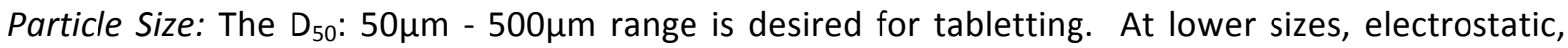
flow $^{19}$ and adhesion issues can be seen. At higher sizes, weight control of tablets and capsules can be challenging. It is however possible to process lower particle sizes with appropriate processing strategies.

Morphology: Needles and plates are more challenging; therefore an aspect ratio closer to 1:1:1 is preferred ${ }^{20}$. Smoothness and roughness of surface are also factors especially at the extremes. Very smooth particles for example could be challenging as they may remain separate from carriers which could lead to content uniformity (CU) challenges.

Surface Area: As both particle size and shape are usually important surface area could be a useful parameter that combines both particularly if surface chemistry effects are found to be important.

Form: A stable solid state form is needed because lack of form control (such as conversion to a more stable polymorph) can lead to changes in material properties with associated manufacturing challenges. This can in turn impact the desired final performance and stability ${ }^{21}$. An example of an API with form issues is given under the Class 4 OT section.

Density: Density of API can also act as a descriptor for assessing suitability for manufacturing. Various compendial methods exist for the measurement of true, bulk and tapped density ${ }^{22}$. Overall, powder density parameters are useful for the derivation of compressibility, flow, and compaction properties of powders.

Other parameters which can affect developability include:

Flow: Flow of particles is important. The Carr Index, or compressibility test, is one of the more easily conducted tests, and is linked to recognised pharmacopeial definitions for flow (Figure 2a). More 
sophisticated tests by shear cell testing to measure flow functions, angles of internal friction or wall friction can give more detailed analysis over a wider range of operating conditions (Figure $2 b$ ).

Segregation: It is known that differences in particle size, shape, surface charge, cohesivity and bulk density promote segregation. However, translating these values to quantify a risk of segregation is difficult due to the multifactorial nature of these interactions. The impact of API particle size on solid dosage form content uniformity can be assessed by a Monte Carlo style simulation ${ }^{23,24}$. Similarly, for granulation, the impact of segregation on content uniformity can be assessed by means of sieve assay methodology $y^{25}$.

Compression assessment: The tablettability (tensile strength versus compaction pressure) and compactability (tensile strength versus solid fraction) of the finished granule or blend are key outputs and dependent on the API, excipients and processing. As a general guide, if the finished tablet has tensile strength of $>1.7 \mathrm{MPa}$ at a solid fraction of $<0.9$, then the tablet will typically be robust to further processing such as film coating, packaging, transport and handling by the patient ${ }^{26}$. The expected solid fraction for a tablet is normally in the range $0.85+/-0.05^{27,28}$. Above this range, there is increased risk of capping and lamination due to localised high density regions. Lower solid fraction would not normally be an issue assuming that all the other tablet properties were acceptable (e.g. friability).

More in-depth analysis can examine and classify the properties of the API in terms of ductility, brittleness, plasticity, elasticity, strain rate sensitivity etc. The generation of these values is very much equipment- and methodology-dependent but such approaches can be useful in the characterisation of API. An example of such an approach described by Roberts and Rowe ${ }^{29}$ is illustrated in Figure 3.

Surface Adhesion: Surface adhesion values will change depending on the methodology of determination. A number of differing approaches can be used: for example, direct measurement of sticking forces such as ejection force, take off force, and adhesion punches via instrumented presses/simulators. Alternatively, the adhered material can be analysed by visual observation ${ }^{30}$, optical microscopy, scanning electron microscopy (SEM) or atomic force microscopy (AFM). However, the values obtained from such experiments might not completely represent the behaviour in dynamic environments, such as during flow, mixing etc. Other approaches include weight ${ }^{31}$ or assay $^{32,33}$ of powder.

\section{Guiding Principles for Construction of a MCS}

The aim of the proposed MCS is to set broad guidelines based on current knowledge using material properties to classify manufacturing risk. It is not intended to be composed of hard rules, but rather a guide to assess risk; based on the properties of the API, the intended dosage form and the proposed manufacturing route. As progression is made down the first three categories, the dependence on initial API properties is reduced reflecting the goal of the granulation process which is to move the properties of the granule closer to the desired zone of developability properties in Table 1.

A key challenge is differentiating the API properties from the particle properties of the formulated granule construct or particle and the resulting interactions with the manufacturing process. Any 
classification system could become extremely complicated if the full range of properties and potential interactions were to be considered. Its value and usage would be reduced if attempting to factor in all actual and theoretical considerations. Instead, the aim is to develop an initial classification scheme that is simple to understand and apply but still covers the most important aspects. Once established, this MCS system can then be further developed.

\section{Category 1: Direct compression (DC)}

DC uses two primary process steps (mixing and compression) and is considerably less complicated than DG or WG (Figure 1). However, it is likely to be the most reliant on initial API particle properties for successful execution. A further challenge for DC is that not only should the API have acceptable properties but these properties should be consistent. Mean particle size and distribution, together with particle shape are particularly critical for direct compression. Unfavourable API particle size and shape are bigger hurdles for DC formulations compared to granulation approaches as there is no subsequent processing step to mitigate those unfavourable API properties. Table 2 outlines the properties of an ideal DC material as proposed by Hancock in $2004^{34}$. Future work for the MCS project initiative will involve updating these criteria in the light of recent knowledge.

\section{Category 2: Dry Granulation (DG)}

DG (roller compaction or slugging) is usually regarded as more forgiving of input particle properties than DC because it has an additional compression step where the API is granulated with the other excipients by partial densification. Most of the desired properties of the API identified for DC are also applicable to DG with the exception of properties associated with flow or bulk density. However, the additional compression step may be disadvantageous for materials with potentially limited compressibility. Therefore, the impact that partial densification has on the finished tablettability of the formulation must be taken into account. Two approaches to risk assessment of this effect are to determine how much the tablettability of the particle is reduced by DG, or to ensure that the remaining tablettability is sufficient to form a robust tablet i.e. in excess of 1.7 $\mathrm{MPa}^{24}$. Typically, it is found that the tensile strength of the ribbon or slug should be above $1 \mathrm{MPa}$ to ensure adequate mechanical strength for milling. DG may be better for elastic materials than DC because DG utilises a slower compression process and can remove some of the elasticity (strain rate sensitivity) allowing the resulting granules to behave better during tabletting compared to the initial powder blend. Particle size of the input API must also be considered because it might impact content uniformity. Likely factors to consider are listed in Table 3.

\section{Category 3: Wet granulation (WG)}

WG is a more complex process than either DC or DG but is able to handle a wider range of API properties and transform the API into granules with superior properties in terms of downstream processability. Given the wide range of process variables and complexity, the main wet granulation method considered for the current benchmarking purpose will be high shear granulation due to the ubiquity of its usage across the industry compared to other approaches such as Fluid Bed, Low Shear, Hot Melt, Steam and Foam etc.

Another assumption is that the granulating liquid is water or water/co-solvent. Applying the concept of percolation threshold, some physical properties are strong drivers for or against wet 
granulation. The list summarised in Table 4 is an example of what needs to be the basis of a risk assessment, together with tentative ranges.

\section{Category 4: Other Technologies (OT)}

OT refers to strategies needed for APIs that fall outside the developability criteria already outlined. It is important to note that these strategies are purely those used to improve manufacturability. Therefore, for example, strategies such as amorphous spray-dried dispersions (SDDs) are not covered if the primary intention of such a strategy is to improve bioavailability even if they have the secondary effect of improving processability ${ }^{33}$.

This category necessarily covers a diverse range of technologies which is best illustrated by particular examples and is not intended to be an exhaustive list. In this section, we have highlighted examples of API properties which made them unsuitable for conventional manufacturing processes. Only techniques which have been applied at a close-to-commercial scale will be described.

High-drug load, moisture-sensitive API: Melt granulation is a process where the API is subjected to temperatures below that of its melting temperature but above the melting point or glass transition temperature of the binder. One study described the evaluation of different processing techniques for a poorly-soluble oncology candidate ${ }^{35}$. As this API was moisture-sensitive, wet granulation was not feasible. Melt granulation improved granule flow properties with fewer fines and allowed for higher drug loadings compared to DG. Other studies using imatinib ${ }^{36}$ and metformin ${ }^{37}$ achieved satisfactory granule properties with drug loadings of up to $90 \%$.

API prone to degradation: Traditional processing of the peroxisome proliferator-activated receptor (PPAR) agonist peglitazar was not possible due to acid and base-catalysed degradation ${ }^{38}$. An active film-coating approach was explored where the drug was added with the film-coating material and sprayed onto tablet cores. This approach yielded tablets with satisfactory chemical stability which was attributed to the higher drug-to-excipient ratio in the film coat containing non-reactive coating materials, compared to that in the traditional DG or WG formulations.

Highly potent drugs: Highly potent drugs pose a safety challenge particularly when dealing with the material in powder form. In addition, their associated low doses can pose a content uniformity challenge. Modifications to the wet granulation process by dissolving the drug in the granulation fluid can overcome this issue ${ }^{39}$. If this is not feasible then the Liquid Dispensing Technology (LDT) method can be used where a solution of the drug is deposited on an inert tablet core ${ }^{40}$.

Form challenges : The HIV pharmacokinetic booster cobicistat is not isolated as the crystalline form but as an amorphous, hygroscopic solid form of low glass transition temperature ${ }^{41}$. This form readily transforms under ambient conditions via a moisture- and temperature-driven phase transformation into a rubber-like material that is difficult to process. Removal of the adsorbed moisture does not lead to reversion to the original solid form. A free-flowing powder is obtained by adsorbing onto silica following evaporation from a dichloromethane solution as part of the API isolation. Although still hygroscopic, moisture uptake is now reversible and it no longer undergoes phase transformation.

Another common form issue involves API which is liquid at room temperature. In order to use a standard manufacturing technique, large amounts of excipients may be needed to convert the API 
into a suitable powder, which in turn can lead to an impractically large dosage form. Liquid or semisolid filled capsules have been used for several commercial products such as fish oils and Vitamin $\mathrm{E}$, to overcome this challenge ${ }^{42}$.

\section{Graphical representation of risk}

The aim of the MCS is to facilitate classification of risk with respect to key physical properties. One approach to aid this is to represent risk graphically. As part of developing the concept, several such approaches have been explored. Parallel coordinate plots (Figure 4a) or spider plots (Figure 4b) can be used to view all the key physical properties holistically as well as score or rank these with respect to extent of manufacturability risk. These provide a quick overview of the level of risk (i.e. how much of the plot is in a high risk region) and also helps to identify the problematic physical properties and likely failure modes. Alternatively, a risk analysis score can be calculated based on relevant API attributes and drug product target attributes. The overall score can be used to identify appropriate processing strategies (Figure 4c).

\section{Further work}

This paper gives an outline of an MCS approach based on current knowledge available in the literature. Further input is needed focussing on the following areas:

- More data on input API properties and resulting particulate and formulation properties could be shared or generated through focused experiments to validate and assess the advantages and limitations of the MCS.

- Additional data could also enable the subdivision of the developability space into zones best represented by DC, DG and WG.

- Construction of Target Material Profiles would inform API optimisation, thus moving it from one process zone to another.

- Surrogate materials could be identified which would represent the different process zones: this would give flexibility as each individual organisation could use these materials to set their own favoured parameters using their own characterisation techniques.

- Ideally the work should be extended to exploit modelling tools for predicting formulation and manufacturing outcomes starting with molecular structure, intrinsic and behavioural material properties.

The challenge for these future efforts will be to strike a balance between a system which is simple enough to apply whilst still capturing all the important factors.

\section{Summary}

In this paper, a proposal is made to develop a MCS. It is further proposed to identify the likely key parameters of a MCS with a suggestion of potential values. The concepts of developability and percolation threshold have been introduced with parameters defined. These values would be expected to vary with the individual API and formulation and would be assessed by a risk analysis 
approach. No single approach would be expected to be best for all situations, but a framework has been created detailing the key factors to be considered in risk-assessing the development of a compound and its interactions with a manufacturing route. This tool is meant to complement the application of $\mathrm{QbD}$ by assisting with the rational selection of manufacturing processes for drug product. Further work and sharing of data are needed to provide greater detail and confidence in this proposal. We encourage input from interested parties on how to improve and apply this paradigm in particular to detail the API properties they feel are important when selecting or modifying API to enable drug product manufacture.

\section{Acknowledgements}

The authors would like to thank Linda Hakes and Bruno Hancock for their helpful comments. 
Tables

Table 1: Desired properties of an API for consideration as a DC, DG or WG solid dosage form

\begin{tabular}{|c|c|c|}
\hline Property & Value & Source \\
\hline Melting Point & $>90^{\circ} \mathrm{C}$ & Ibuprofen Mpt $76{ }^{0} \mathrm{C}^{43}$ \\
\hline Contact angle Water & $<90^{\circ}$ & Usual accepted point of wetting \\
\hline Moisture uptake & $\begin{array}{c}<1 \% \text { weight change over manufacturing } \\
\text { humidity and temp range }\end{array}$ & Idealised \\
\hline Dose number & $<250 \mathrm{~mL}$ & BCS classification system \\
\hline Bulk density & $\begin{array}{c}>0.3 \mathrm{~g} / \mathrm{mL} \text { (equivalent to } 0.21 \text { solid } \\
\text { fraction of a } 1.4 \mathrm{~g} / \mathrm{mL} \text { true density } \\
\text { material). }\end{array}$ & Manufacturing Efficiency \\
\hline Stability / Compatibility & $\begin{array}{c}>2 \text { years at room temp. Compatibility } \\
\text { with common pharmaceutical } \\
\text { excipients. }\end{array}$ & Idealised \\
\hline Particle size & 50 to 500 microns & Idealised \\
\hline Morphology & Aspect ratio $1: 1: 1$ & Idealised \\
\hline Form & $\begin{array}{l}\text { Stable under standard manufacturing } \\
\text { environmental conditions }\end{array}$ & Idealised \\
\hline
\end{tabular}


Table 2: Properties of an Ideal Direct-Compression Material

Adapted from McCormick $2005^{34}$ from a talk given by BC Hancock "Identifying candidates for direct compression using material-sparing formulation tools" presented at AAPS November 2004.

\begin{tabular}{ccc}
\hline Property & Value & Target Value \\
\hline Particle Size and Shape & D 4,3 (mean volume diameter) & $>80 \mu \mathrm{m}$ \\
& D 10 (10th percentile diameter) & $>30 \mu \mathrm{m}$ \\
& D 90 (90th percentile diameter) & $\leq 1000 \mu \mathrm{m}$ \\
Blend Uniformity & Aspect Ratio & $<1.5$ \\
Powder Flow & Blend Potency & $<2 \%$ relative standard deviation \\
& Effective angle of internal & $<41^{\circ}$ \\
Powder density & friction & \\
Tableting performance & True & $1.0-2.5 \mathrm{~g} / \mathrm{mL}$ \\
& Bulk & $>0.5 \mathrm{~g} / \mathrm{mL}$ \\
& Dwell time sensitivity & Low \\
& Precompression force & $20-125 \mathrm{MPa}$ \\
Compact mechanical properties & Compression stress & \\
(at $\sim 0.85$ solid fraction) & (at $\sim 0.85$ solid fraction) & $>1.0 \mathrm{MPa}$ \\
& Tensile strength & $<0.2$ \\
& Brittle fracture index & $75-250 \mathrm{MPa}$ \\
\hline
\end{tabular}

Table 3: Properties of an Ideal Roller Compaction Material

\begin{tabular}{ccc}
\hline Property & Value & Target Value \\
\hline Compactability & At 0.7 solid fraction & $>1 \mathrm{MPa}$ \\
Loss of compressibility & Compressibility remaining in granules & $>1.7 \mathrm{MPa}$ \\
Bulk density & At $>0.14$ solid fraction & $>0.2 \mathrm{~g}$ per $\mathrm{mL}$ \\
Too low friction (no grip) & Angle of wall friction & $<20$ degrees \\
Flow assessment & Flow function coefficient & $>4$ \\
Solid State Properties & Carr's Index & $<35 \%$ \\
& Melting point & $>90{ }^{\circ} \mathrm{C}$ \\
Particle size for CU & Glass Transition $(\mathrm{Tg})$ & $>90{ }^{\circ} \mathrm{C}$ \\
Stability With Excipients & Loss of crystallinity during compaction & None \\
\hline & Blend potency & Meets Rohr's criteria \\
& Acceptable Stability & $>2$ years at room temp \\
\hline
\end{tabular}

Table 4: Key Considerations for Selection of Wet Granulation

Colours denote level of risk factor. 


\begin{tabular}{|c|c|c|c|c|c|}
\hline \multirow[t]{2}{*}{ Property } & \multirow[t]{2}{*}{ Condition } & \multicolumn{3}{|c|}{ Drug Loading } & \multirow[t]{2}{*}{ Comment } \\
\hline & & Low & Medium & High & \\
\hline Low Density & & & $\begin{array}{l}\text { Driver } \\
\text { for WG }\end{array}$ & $\begin{array}{l}\text { Driver } \\
\text { for } \\
\text { WG }\end{array}$ & \\
\hline Poor Wettability & & $\begin{array}{l}\text { Driver } \\
\text { for } \\
\text { WG }\end{array}$ & $\begin{array}{l}\text { Driver } \\
\text { for WG }\end{array}$ & $\begin{array}{l}\text { Driver } \\
\text { for } \\
\text { WG }\end{array}$ & $\begin{array}{l}\text { Wet gran may improve } \\
\text { dissolution rate and } \\
\text { manufacturability }\end{array}$ \\
\hline Moisture Sensitivity & & $\mathrm{H}$ & $\mathrm{H}$ & $\mathrm{H}$ & High Risk \\
\hline \multirow[t]{3}{*}{ Morphology } & Plates & L & $\mathrm{M} / \mathrm{H}$ & $\mathrm{H}$ & Can have capping \\
\hline & Needles & $\mathrm{L}$ & $\mathrm{H}$ & $\mathrm{H}$ & $\begin{array}{l}\text { problems: May need to } \\
\text { mill / recrystallise API }\end{array}$ \\
\hline & Equant & L & $\mathrm{L}$ & $\mathrm{L}$ & \\
\hline \multirow[t]{3}{*}{$\begin{array}{l}\text { Deformation } \\
\text { Mechanism }\end{array}$} & Elastic & $\mathrm{L}$ & L/M & $\mathrm{M} / \mathrm{H}$ & $\begin{array}{l}\text { The greater the elastic } \\
\text { component the higher }\end{array}$ \\
\hline & Plastic & L & L & $\mathrm{L}$ & the risk: May need to mill \\
\hline & Brittle & $\mathrm{L}$ & $\mathrm{L}$ & $\mathrm{L}$ & / recrystallise API \\
\hline \multirow[t]{2}{*}{ Solubility Interaction } & $\begin{array}{l}\text { Binder Interaction } \\
\text { Aids Release }\end{array}$ & L & $\mathrm{L}$ & $\mathrm{L}$ & \\
\hline & $\begin{array}{l}\text { Binder Interaction } \\
\text { Slows Release }\end{array}$ & L/M & M & $\mathrm{H}$ & \\
\hline $\begin{array}{l}\text { Polymorph / Hydrate } \\
\text { Formation }\end{array}$ & & $\mathrm{M} / \mathrm{H}$ & $\mathrm{M} / \mathrm{H}$ & $\mathrm{M} / \mathrm{H}$ & $\begin{array}{l}\text { Polymorphic changes } \\
\text { due to the presence of } \\
\text { solvent }\end{array}$ \\
\hline \multirow[t]{2}{*}{ Melting Range } & $<90^{\circ} \mathrm{C}$ & L & L/M & $\mathrm{M} / \mathrm{H}$ & \\
\hline & $>90^{\circ} \mathrm{C}$ & L & L & L & \\
\hline Poor Flow & & $\begin{array}{l}\text { Driver } \\
\text { for } \\
\text { WG }\end{array}$ & $\begin{array}{l}\text { Driver } \\
\text { for WG }\end{array}$ & $\begin{array}{l}\text { Driver } \\
\text { for } \\
\text { WG }\end{array}$ & \\
\hline $\begin{array}{l}\text { High tendency to } \\
\text { segregate }\end{array}$ & & $\begin{array}{c}\text { Driver } \\
\text { for } \\
\text { WG }\end{array}$ & $\begin{array}{l}\text { Driver } \\
\text { for WG }\end{array}$ & $\begin{array}{l}\text { Driver } \\
\text { for } \\
\text { WG }\end{array}$ & \\
\hline
\end{tabular}




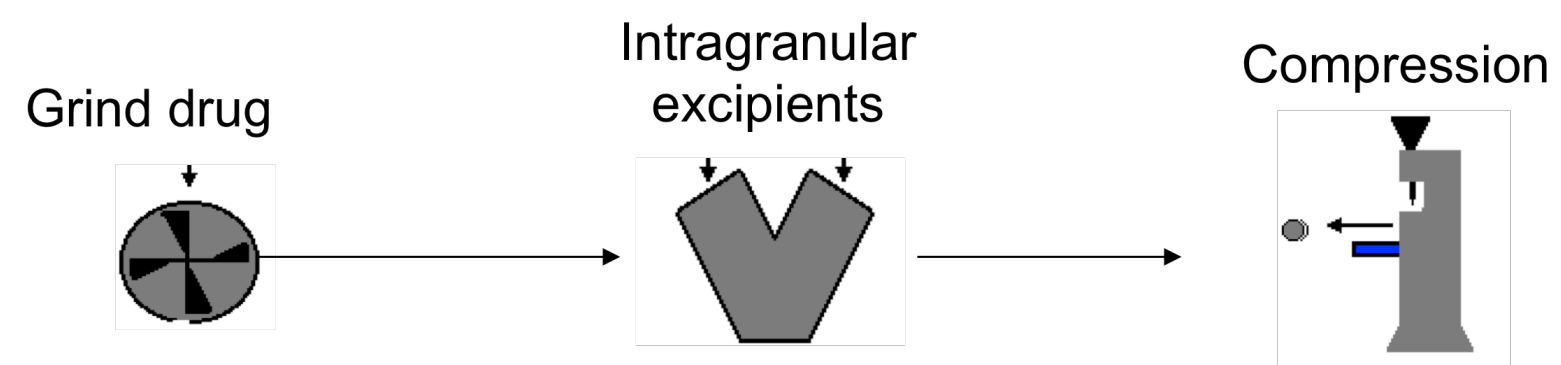

Figure 1a

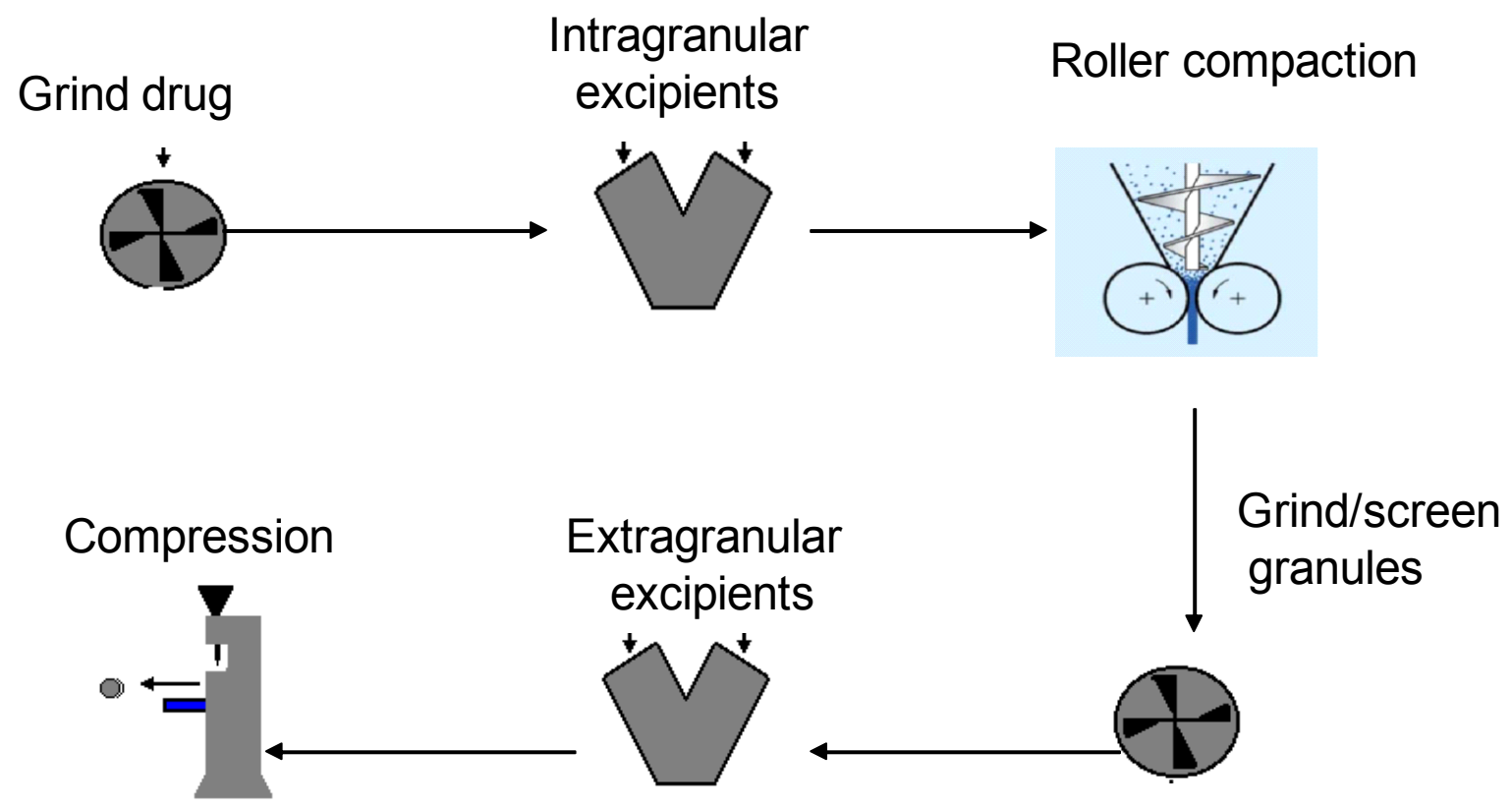

Figure $1 b$ 


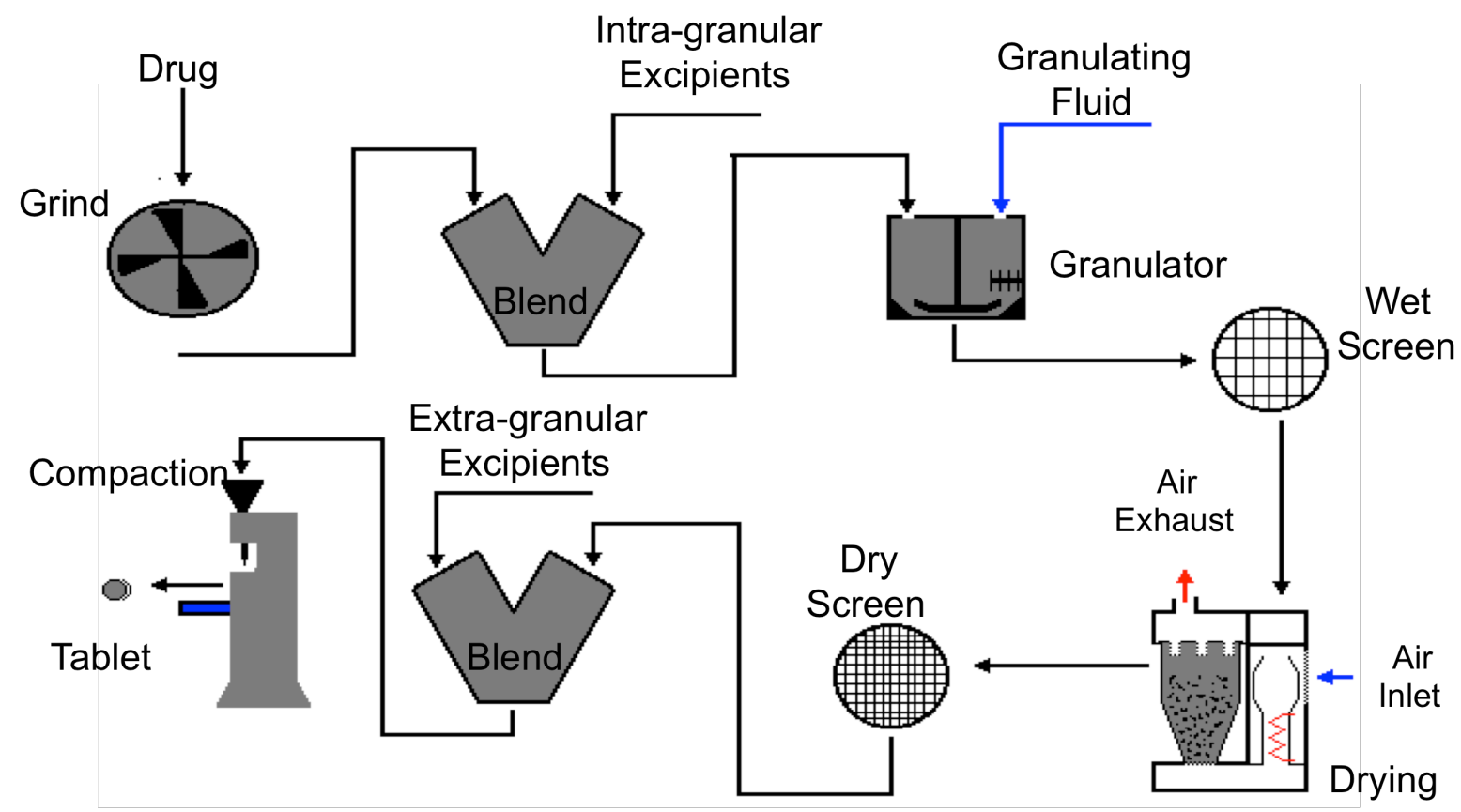

Figure 1c

Figure 1: Schematics of (a) Direct Compression (b) Dry Granulation (c) Wet Granulation Processes 


$\left.\left.\left.\left.\left.\begin{array}{c|c}>38 \\ \text { Very very poor }\end{array}\right\rangle \begin{array}{c}32-37 \\ \text { Very poor }\end{array}\right\rangle \begin{array}{c}26-31 \\ \text { Poor }\end{array}\right\rangle \begin{array}{c}21-25 \\ \text { Passable }\end{array}\right\rangle \begin{array}{c}16-20 \\ \text { Fair }\end{array}\right\rangle$ Excellent

\section{1-2 Very cohesive $\quad$ 2-4 Cohesive $>4-10$ Easy Flowing $>>10$ Free Flowing}

Figure 2 (a) USP monograph values for Carr's Index ${ }^{45}$ (b) Flow Function Table ${ }^{46}$ 


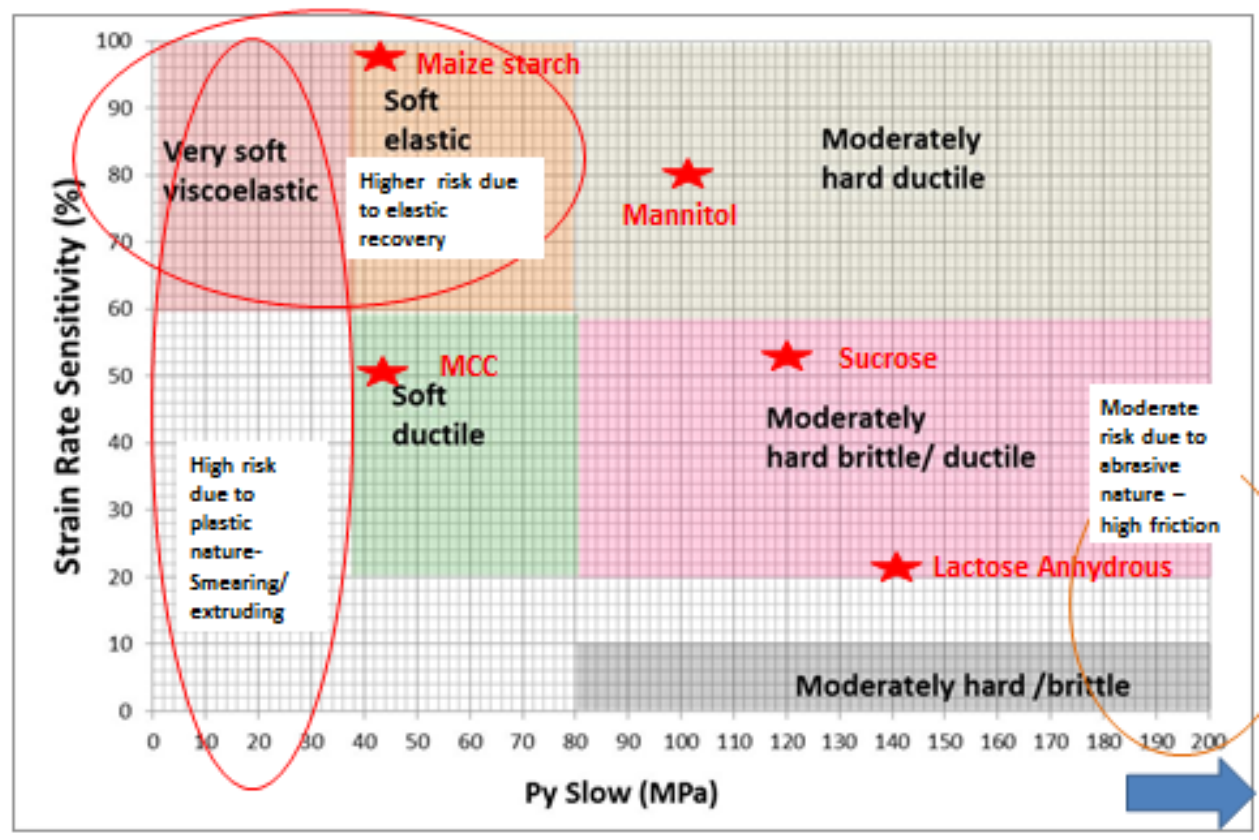

Figure 3: Compaction Classification by Material Properties

(Adapted from Roberts and Rowe) $^{29}$ 


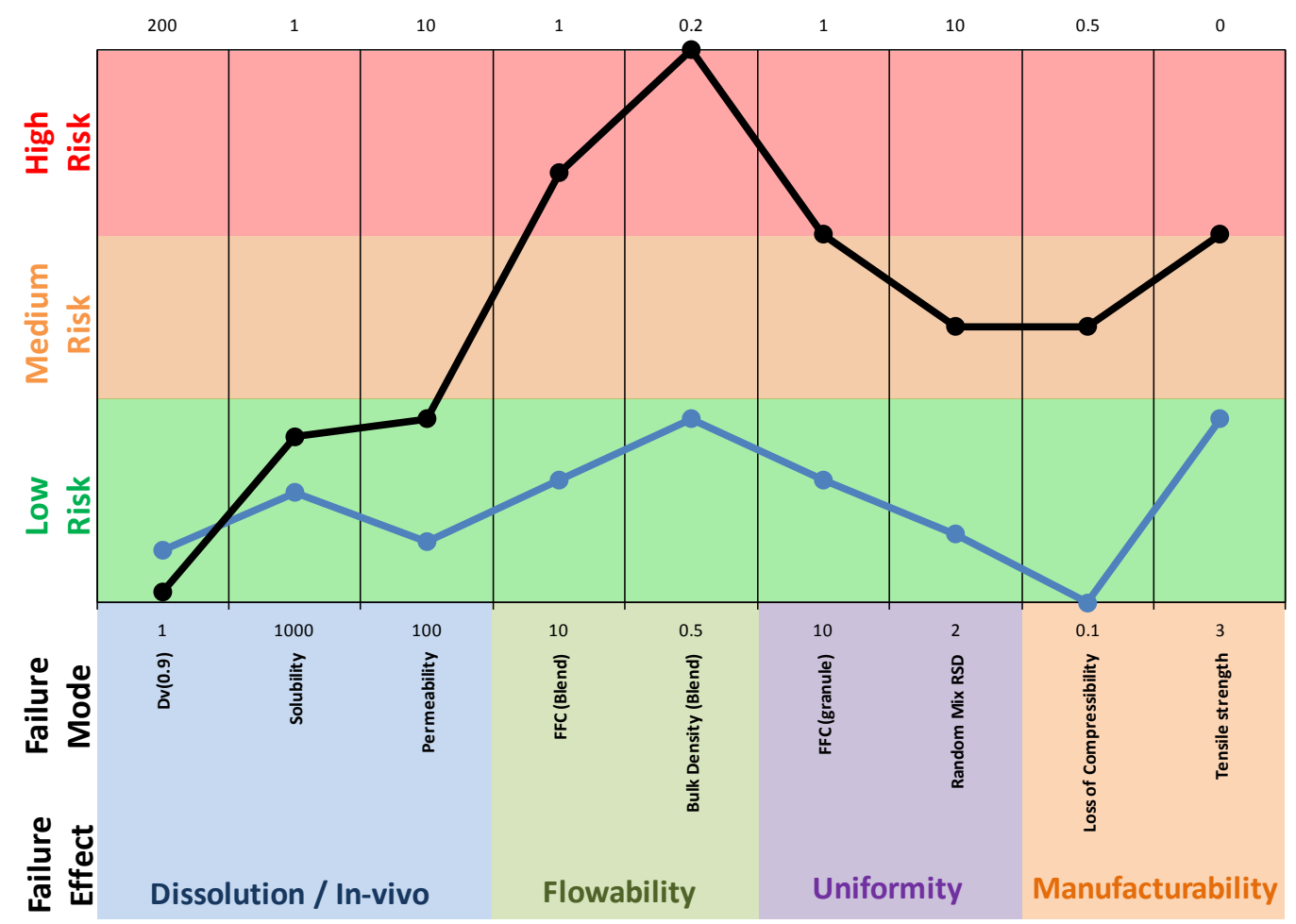

Figure 4(a)

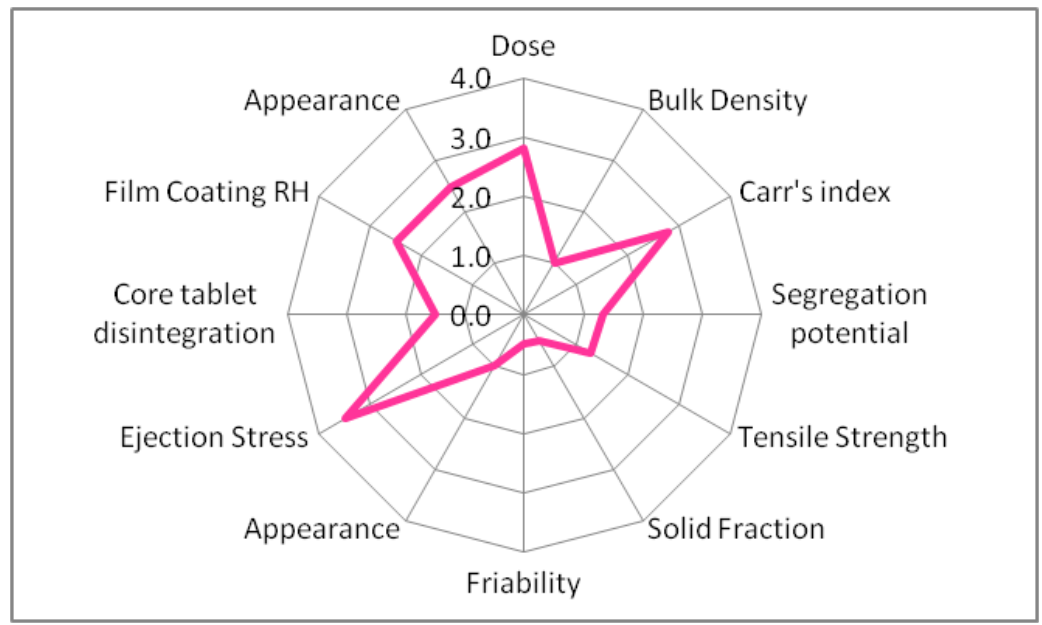

Figure 4(b) 


\section{Risk Analysis}

- Risk analysis score based on relevant API properties and drug product target attributes (link to TPP) . Overall score used to identify appropriate manufacturing methods.

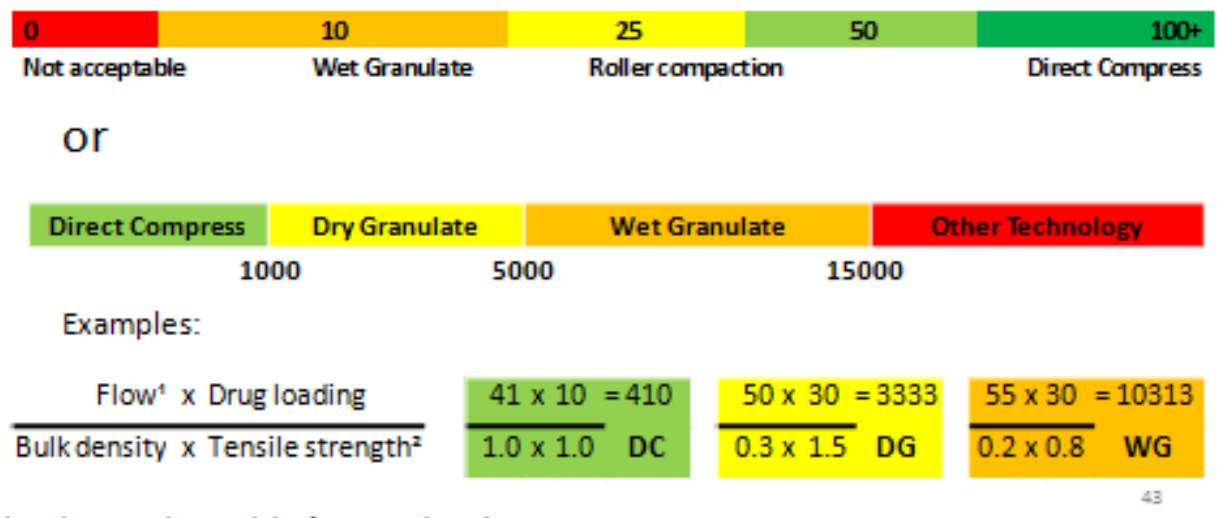

Figure 4(c)

Figure 4: Tools to Visualise Risk in Respect of Different Properties (a) Parallel Co-ordinates Charts (b) Spider Plots (c) Risk Analysis.*

* The examples given are for illustration only and do not refer to any particular API. 


\section{References}

1. Amidon GL, Lennernas H, Shah VP, Crison JR. A theoretical basis for a biopharmaceutic drug classification: The correlation of in vitro drug product dissolution and in vivo bioavailability. Pharm Res. 1995;12(3):413-20.

2. Kawabata Y, Wada K, Nakatani M, Yamada S, Onoue S. Formulation design for poorly watersoluble drugs based on biopharmaceutics classification system: Basic approaches and practical applications. Int J Pharm. 2011;420(1):1-10.

3. Sacks LV, Shamsuddin HH, Yasinskaya YI, Bouri K, Lanthier ML, Sherman RE. Scientific and regulatory reasons for delay and denial of FDA approval of initial applications for new drugs, 20002012. JAMA. 2014;311(4):378-84.

4. Bellamy LJ, Nordon A, Littlejohn D. Effects of particle size and cohesive properties on mixing studied by non-contact NIR. Int J Pharm. 2008;361(1-2):87-91.

5. Olusanmi D, Jayawickrama D, Bu D, McGeorge G, Sailes H, Kelleher J, Gamble JF, Shah UV, Tobyn M. A control strategy for bioavailability enhancement by size reduction: Effect of micronization conditions on the bulk, surface and blending characteristics of an active pharmaceutical ingredient. Powder Technol. 2014;258:222-33.

6. Kim S, Wei C, Kiang S. Crystallization Process Development of an Active Pharmaceutical Ingredient and Particle Engineering via the Use of Ultrasonics and Temperature Cycling. Org Process Res Dev. 2003;7(6):997-1001.

7. Waknis V, Chu E, Schlam R, Sidorenko A, Badawy S, Yin S, Narang AS. Molecular basis of crystal morphology-dependent adhesion behavior of mefenamic acid during tableting. Pharm Res. 2014;31(1):160-72.

8. Carstensen JT, Chan PC. Relation between particle size and repose angles of powders. Powder Technol. 1976;15(1):129-31.

9. Lam KK, Newton JM. Influence of particle size on the adhesion behaviour of powders, after application of an initial press-on force. Powder Technol. 1992;73(2):117-25.

10. lacocca RG, Burcham CL, Hilden LR. Particle engineering: A strategy for establishing drug substance physical property specifications during small molecule development. J Pharm Sci. 2010;99(1):51-75.

11. Wildfong PLD, Morris KR, Anderson CA, Short SM. Demonstration of a shear-based solidstate phase transformation in a small molecular organic system: Chlorpropamide. J Pharm Sci. 2007;96(5):1100-13.

12. Schmidt AG, Wartewig S, Picker KM. Potential of carrageenans to protect drugs from polymorphic transformation. Eur J Pharm Biopharm. 2003;56(1):101-10.

13. Morris KR, Griesser UJ, Eckhardt CJ, Stowell JG. Theoretical approaches to physical transformations of active pharmaceutical ingredients during manufacturing processes. Adv Drug Deliver Rev. 2001;48(1):91-114.

14. Descamps M, Willart JF, Dudognon E, Caron V. Transformation of pharmaceutical compounds upon milling and comilling: The role of Tg. J Pharm Sci. 2007;96(5):1398-407.

15. Leane MM, Sinclair W, Qian F, Haddadin R, Brown A, Tobyn M, Dennis AB. Formulation and process design for a solid dosage form containing a spray-dried amorphous dispersion of ibipinabant. Pharm Dev Technol. 2013;18(2):359-66.

16. Airaksinen S, Karjalainen M, Kivikero N, Westermarck S, Shevchenko A, Rantanen J. Excipient selection can significantly affect solid-state phase transformation in formula wet granulation. AAPS PharmSciTech. 2005;6(2).

17. Leuenberger $\mathrm{H}$. The application of percolation theory in powder technology. Adv Powder Technol. 1999;10(4):323-52.

18. Stepan AF, Walker DP, Bauman J, Price DA, Baillie TA, Kalgutkar AS, Aleo MD. Structural alert/reactive metabolite concept as applied in medicinal chemistry to mitigate the risk of idiosyncratic drug toxicity: A perspective based on the critical examination of trends in the top 200 drugs marketed in the United States. Chem Res Toxicol. 2011;24(9):1345-410. 
19. Tan SB, Newton JM. Powder flowability as an indication of capsule filling performance. Int J Pharm. 1990;61(1-2):145-55.

20. Danjo K, Kinoshita K, Kitagawa K, lida K, Sunada H, Otsuka A. Effect of particle shape on the compaction and flow properties of powders. Chem Pharm Bull. 1989;37(11):3070-3.

21. Leane MM, Gamble JF, Brown J, Hughes H, Crull G, Engstrom J, Gao Q, Bunker M, Rutherford $S$, Parker A, Roberts CJ, Tobyn M. Imaging dehydration kinetics of a channel hydrate form of the HIV1 attachment inhibitor prodrug BMS-663068. J Pharm Sci. 2013;102(12):4375-83.

22. Abdullah EC, Geldart D. The use of bulk density measurements as flowability indicators. Powder Technol. 1999;102(2):151-65.

23. Rohrs BR, Amidon GE, Meury RH, Secreast PJ, King HM, Skoug CJ. Particle size limits to meet USP content uniformity criteria for tablets and capsules. J Pharm Sci. 2006;95(5):1049-59.

24. Yalkowsky SH, Bolton S. Particle size and content uniformity. Pharm Res. 1990;7(9):962-6.

25. Thiel WJ, Nguyen LT. Fluidized bed granulation of an ordered powder mixture. J Pharm Pharmacol. 1982;34(11):692-9.

26. Pitt KG, Heasley MG. Determination of the tensile strength of elongated tablets. Powder Technol. 2013;238:169-75.

27. Hancock BC, Colvin JT, Mullarney MP, Zinchuk AV. The relative densities of pharmaceutical powders, blends, dry granulations and immediate-release tablets. Pharmaceutical Technology. 2003;April:64-80.

28. Makino T. Advances in tabletting technology. Pharm Tech Japan. 2009;25:1625-32.

29. Roberts RJ, Rowe RC. The compaction of pharmaceutical and other model materials - a pragmatic approach. Chem Eng Sci. 1987;42(4):903-11.

30. Wang JJ, Li T, Bateman SD, Erck R, Morris KR. Modeling of adhesion in tablet compression - I. Atomic force microscopy and molecular simulation. J Pharm Sci. 2003;92(4):798-814.

31. Mullarney MP, Macdonald BC, Hutchins A. Assessing Tablet-Sticking Propensity: Weighing accumulated powder on a removable punch tip. Pharm Technol Eur. 2012;36:57-62.

32. Roberts M, Ford JL, MacLeod GS, Fell JT, Smith GW, Rowe PH. Effects of surface roughness and chrome plating of punch tips on the sticking tendencies of model ibuprofen formulations. J Pharm Pharmacol. 2003;55(9):1223-8.

33. McDermott TS, Farrenkopf J, Hlinak A, Neilly JP, Sauer D. A material sparing method for quantitatively measuring tablet sticking. Powder Technol. 2011;212(1):240-52.

34. McCormick D. Evolutions in direct compression. Pharmaceutical Technology. 2005;29(4):52-

62.

35. Dalziel G, Nauka E, Zhang F, Kothari S, Xie M. Assessment of granulation technologies for an API with poor physical properties. Drug Dev Ind Pharm. 2013;39(7):985-95.

36. Vasanthavada $M$, Wang $Y$, Haefele $T$, Lakshman JP, Mone $M$, Tong W, Joshi YM, M. Serajuddin AT. Application of melt granulation technology using twin-screw extruder in development of high-dose modified-release tablet formulation. J Pharm Sci. 2011;100(5):1923-34.

37. Lakshman JP, Kowalski J, Vasanthavada M, Tong WQ, Joshi YM, Serajuddin ATM. Application of melt granulation technology to enhance tabletting properties of poorly compactible high-dose drugs. J Pharm Sci. 2011;100(4):1553-65.

38. Desai DS, Rao V, Guo H, Li D, Stein D, Hu FY, Kiesnowski C. An active film-coating approach to enhance chemical stability of a potent drug molecule. Pharm Dev Technol. 2012;17(2):227-35.

39. Desai D, Li D, Harianawala A, Sprockel O, Huang M, Timmins P. Solubilization of entecavir by povidone to overcome content uniformity challenges for low-dose tablet formulations. Pharm Dev Technol. 2013;18(6):1305-13.

40. Richardson M, Wilson M. Liquid Dispensing Technology (LDT) - Summary Presentation http://www.ddfevent.com/pdf/MartinRichardson\&MarkWilson.pdf: G.S.K.; 2013 [cited 2014 April 10th].

41. Timmins P, Brown J. Formulation Technology Enables the Delivery of HIV Medicines. European Industrial Pharmacy Journal. 2013;19 12-7. 
42. Cole ET, Cadé D, Benameur H. Challenges and opportunities in the encapsulation of liquid and semi-solid formulations into capsules for oral administration. Adv Drug Deliver Rev.

2008;60(6):747-56.

43. Merck Index (12th Edition). Budavari, editor. Whitehouse Station, NJ.: Merck Research Laboratories; 1996.

44. Wells Jl. Pharmaceutical Preformulation: The Physicochemical Properties of Drug

Substances. Rubinstein MH, editor. Chichester: Ellis Horwood Limited; 1988.

45. United States Pharmacopeia and National Formulary. USP 36-NF 31. Rockville, MD.: United States Pharmacopeia Convention; 2013. p. 1174 Powder Flow.

46. Jenike A. Storage and Flow of Solids. Utah, University of. 1964. 